\title{
Troubling Care: Four Orientations for Wickedness in Design
}

\author{
Karey Helms \\ KTH Royal Institute of Technology \\ Stockholm, Sweden \\ karey@kth.se
}

\author{
Ylva Fernaeus \\ KTH Royal Institute of Technology \\ Stockholm, Sweden \\ fernaeus@kth.se
}

\begin{abstract}
Tensions in designing for care are often positioned as conflicts to be resolved. We draw upon queer theories to investigate caring for loved ones as not "in-line" with normative expectations of care as positive and fulfilling. Through the critique of two autobiographical design projects designed for informal, everyday care of our families, we describe four troubling orientations of care: willful detours, selfish shortcuts, naughty invasions, and unhappy departures. From these, we argue that tensions in care may not always be designed against, but can also be desired and generative. We conclude by discussing a "wickedness" in caring for loved ones that problematizes in-home technologies as attractively naughty and potentially violent, and the four orientations as resources for interaction designers to spatially navigate tensions of domestic care.
\end{abstract}

\section{CCS CONCEPTS}

\section{- Human-centered computing $\rightarrow$ Interaction design.}

\section{KEYWORDS}

Care; autobiographical design; home; critique; queer theory; troubling; design research.

\section{ACM Reference Format:}

Karey Helms and Ylva Fernaeus. 2021. Troubling Care: Four Orientations for Wickedness in Design. In Designing Interactive Systems Conference 2021 (DIS '21), June 28-fuly 2, 2021, Virtual Event, USA. ACM, New York, NY, USA, 13 pages. https://doi.org/10.1145/3461778.3462025

\section{INTRODUCTION}

Caring for loved ones has and will likely always be an important domain for interaction design. In light of an ongoing pandemic, our focus foregrounds a recent demand and shared concern worldwide into what care might mean, do, and support as technology continues to enter our homes. Apart from technologies for remote work and homeschooling, relevant examples designed to overcome barriers of physical distance and challenges of isolation include playful networked communicators [59], synchronized music-listening [64], and open-ended resources to empower aging populations [42]. Yet new technologies in the home can also contribute to an unequal distribution of gendered labor [53], and do not always insure that victims of domestic violence are adequately supported [21] or safe from technologically-mediated abuse [10]. This grounds a demand

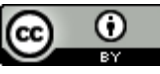

This work is licensed under a Creative Commons Attribution International 4.0 License.

DIS '21, fune 28-fuly 2, 2021, Virtual Event, USA

(c) 2021 Copyright held by the owner/author(s).

ACM ISBN 978-1-4503-8476-6/21/06.

https://doi.org/10.1145/3461778.3462025 to investigate this design space as a wicked problem [52] whereby technological solutions can be both appealingly playful and potentially violent. Thus, during a time when in-home technologies are perhaps increasingly relevant, might interaction design be approaching care too simply?

Care means and does many things, and within its ambivalence of significance and ontology are tensions and contradictions. Among these are moments of discontent, unease, and agony rooted within intents of compassion and goodwill. In Michelle Murphy's call for an "unsettling" of care [45], she cautions against always equating care with positive feelings and encourages recognizing its potential discomfort and non-innocence. Disturbing such assumptions aims toward more critical practices that make accountable romantic techno-science projects, that despite good intentions, often either do not address or normalize painful relations and structures of care. Such entanglements have been increasingly recognized by HCI research that locates power and access within politics of care [11, $23,37]$, and foregrounds unease as a potential byproduct within the emotional labor of research $[6,66]$. Taken together, these growing bodies of work highlight potential negative consequences of care across diverse domains.

This paper builds upon these threads of research into impurities of care. In our alignment with scholarship that aims to make space for it as transformative and troubling $[45,49,50]$, rather than focusing on care giving and receiving as "straight", a gendered repetition of it as positive and fulfilling, we draw upon queer theories $[2,44]$ to explore other ways care might be directed, expected, and aligned. Additionally, we turn our attention towards "everyday" [67] technologically-mediated care at home between family members, which we refer to as caring for loved ones. Such care is not formalized, and is often either unrecognized or devalued as feminine labor [56] that further risks perpetuating stereotypes against divergent care practices [49]. As pointed out by Leah Lakshmi Piepzna-Samarasinha [49], a home can be a sanctuary and refuge, yet the terms "care home" and "home care" are not without associations of vulnerability and abuse.

Thus, designing for care can be described as a wicked problem [52] whereby a careful design for one home might be careless in another home. To investigate this, we ask: How can technologicallymediated care be explored as not "in-line" with normative expectations and directions? As a result, what other orientations of domestic care might emerge? And how might these orientations be a resource for interaction designers navigating tensions of care?

We approach these questions through a reflexive critique of two autobiographical design projects designed for the everyday care of our families. The first project is the deployment and remote monitoring of simple sensors at home to speculate around the well-being of the first author's husband. The second project is a custom smart home system developed by the second author to locally monitor 
her young children when they might be approaching an unsafe area. Within our critique and through a queer phenomenology [2], we approach care at home between loved ones as spatial to account for the bodily ways in which humans and technology are oriented, and use an intimate access from first-perspectives [38] to reflect upon tensions in our care-giving and care-receiving.

The remainder of this paper is organized as follows. We first present an overview of related work on technology in the home and a theoretical grounding of tensions in care. We then describe our methodology, which draws upon interaction criticism and queer theories for a reflexive critique. Next we give first-person descriptions of the autobiographical projects, followed by the critique, through which we illustrate four troubling orientations of technology in the home that are grounded in care as spatial and corresponding tensions: willful detours, selfish shortcuts, naughty invasions, and unhappy departures. We then discuss how these orientations might be a resource for interaction designers and broader reflections on a "wickedness" in care that problematizes in-home technologies as attractively naughty and potentially violent.

\section{BACKGROUND}

\subsection{Tensions in Designing for the Home}

Since Weiser's [71] vision of ubiquitous computer, the home has long been a site for interaction design research. This includes a diverse body of work spanning from efficiency and automation, to safety and monitoring, to pleasure and convenience. While this discourse does not always explicitly position itself as about care, it uses similar components and strategies as that of which is explicitly positioned as about care. This includes "caring" digital assistants [25] that can automate domestic labor, medical devices [39] and baby monitors [24] for in-home health and safety, and intimate communication $[12,40,41,63,70]$ to conveniently bridge distances between loved ones. The overlap in technologies, yet disconnect in intent, highlight fine lines between care and control, surveillance, and abuse.

A growing body of research regarding the ethics of technology in the home [54] amid unpredictable uses [51], can be seen to render technologies for care as unstable. Recent research on parental monitoring of infants [43] has for instance been seen to contribute to a normalization of broader surveillance practices as necessary to a culture of care. In The Smart Wife [56], Kennedy and Strengers give examples that depict how remote-controlled lighting can both be playfully used to tease, or tauntingly used to frighten. Technology meant to build intimacy can instead become creepy. A more subtle example includes how parents care for their children by choosing to either maintain or restrict functionality of technological toys among concerns that they might record media from their home [22]. Together, these examples demonstrate unease as unintentional byproducts rooted in designerly intents of goodwill.

Another challenge of technology in the home in designing for care is turning away from dominant visions and harmful stereotypes $[9,14]$. This can be seen in how technology is often gendered in the home [56, 57, 62], which does not account for divergent care practices or technology that does not fit binary roles. Research that aims to step away from stereotypes in the home includes the resourceful aging project [42] that counters framing the elderly as incompetent, alternative visions of the Internet of Things [17] that broaden definitions and assumptions of the home, and speculating on different forms of domestic life [48] that aims to understand "alternative" values and practices. Our research aligns with getting away from simplified visions of the home and its inhabitants, and recognizing differences that have not been previously considered in this design space.

These challenges and contradictory appeals for and against technology in the context of caring, highlights a "wickedness" that aligns with "wicked problems" [52] as socially complex, inconsistent, and transformative; yet discards categorizing caring for loved ones as a problem to be solved. Devedorf et al. [18] similarly discuss their inclination to frame mothering as a wicked problem, yet ultimately decided not to as it uncomfortably provokes a quest for hegemonic solutions and associates mothering with history of a gendered violence. We instead choose to stay with a "wickedness" within care to accentuate a potential violence of technology, while also opening for divergent practices that might embrace other definitions of wicked as attractively naughty and care as not "in-line" with normative expectations.

\subsection{Tensions of Designing for Care}

We ground our inquiry into care within Joan Tronto and Berenice Fisher's definition of care as "everything that we do to maintain, continue, and repair our 'world' so that we can live in it as well as possible" [68]. In Matters of Care [50], Maria Puig de la Bellacasa revisits this broad definition to articulate three embedded dimensions of care: the labor behind "maintenance", the ethics and politics of a pursuit for a "good" life, and the affective disposition of "as well as possible". Puig de la Bellacasa poses that care does not exist if all three dimensions are not present, exemplified by the affect to "care about" without the work to "care for" that stays in the realm of moral intention [68]. Yet while each is always present, the three dimensions are not always equally distributed [50], which results in tensions between the labor/work, affect/affections, and ethics/politics of care.

In the following, we describe each dimension as a tension, which we exemplify through and with related HCI research that illustrates the complexities and often conflicting experiences of care [65]. We then ground our inquiry within "everyday" informal care at home between loved ones.

2.2.1 Tensions in affect/affection. Caring about someone or something can be considered a basis of care through the discerning of caring needs [69]. This might include caring about a particular child's happiness or more broadly income inequality, both of which imply an affective engagement with the wellbeing of a concern or responsibility. Tensions within the affective side of care might include expectations of performances of care as always "full of motherly love" that can neglect the potential emotional ambivalence of care givers. Examples of this might include a mother feeling obligated to care and feeling bad about it, or a paid care worker who rightfully does not enjoy care labor yet is morally pressured to employ affective engagement [50]. This tension falls under the assumption that care giving and receiving should always feel good. In HCI, this can be seen in research that investigates the empathetic character of researcher-participant relationships [66], and 
that which more specifically recognizes the emotional work within Experience Centered Design as not always positive and in need of practical strategies for navigating [6].

2.2.2 Tensions in labor/work. Care labor can be considered the material practices that support caring. This is often discussed as the concrete tasks of care-giving in addressing caring needs. Tensions of labor might include well-meaning care work that is misdirected by falsely assuming someone or something needs to be maintained, repaired, or fixed, which can infantilize by implying a recipient is incapable, less than, or broken [65]. This can be seen in (dis)ability studies and "crip" care that challenges patronizing approaches and advocates for the inclusion of new care frameworks [20, 49]. In contrast, a tension might also include celebrating well-meaning care labor that should be expected, which can anglify care givers and in turn devalue the needs of care recipients. In HCI, this tension can be seen in research on how the prioritization of task completion in AI and Assistive Technology subverts people with disabilities, and might instead place greater emphasis on interdependent caring relations [11].

2.2.3 Tensions in ethics/politics. As asserted by Joan Tronto, "[c]are is always infused with power" [69]. This includes everyday informal practices such as the care of a child by a parent, to formal relationships between a doctor and patient, to larger political contexts that reflect societal values and polices. All of these are bound within ethical and political questions of what constitutes legitimate, or "good" care, and thus are never neutral [50]. Tensions within an ethics of care might include illegally sharing prescription drugs with a friend who doesn't have medical access, or the exclusion of medical access based on a political agenda [49]. This can be seen in feminist science studies on the politics behind feminist health movements that, through colonial family planning initiatives, determine what lives are worth living, saving, or being born [46]. In $\mathrm{HCI}$, this tension can be seen in research that exposes the politics behind the distribution of menstrual resources in public restrooms [23], and in the manifestations of research subjects' own political agendas within participation [37].

Within the above three descriptions of tensions in care, we situate our research within the everyday caring of loved ones at home. Toombs et al. have highlighted a research gap in "everyday" care that due to its informal and unstructured nature is often neglected [67]. While this "everyday" has a community focus that examines local and extended social networks of care, we turn our focus towards everyday domestic settings that include unpaid, informal day-to-day care that typically takes place at home or within a private familial setting. We further this delineation with a relational focus on "loved ones" that might or might not be family members. Within this context, normative expectations of care often include feminized and heteronormative expectations.

\section{METHODOLOGY}

For our inquiry into the everyday caring of loved ones, we used autobiographical design, interaction criticism, and queering as methods. Autobiographical design [47] is a first-person method in which the researcher is both a designer and user of the system being studied. This choice of method was in response to our individual and genuine needs for the systems developed, and ongoing felt tensions of care from during and after their use that motivated revisiting the projects years later. Our reflexive critique of the two autobiographical projects presented draws upon interaction criticism [7] to revisit and rigorously interrogate relationships between our cultural experiences of domestic care and our design decisions in constructing the systems; and queering $[44,55]$ as a method to trouble normative assumptions within an interplay between craft and reflection. In the following, we further ground our methodological and theoretical commitments.

As autobiographical designs, both projects draw upon first-person perspectives [38] for intimate access to the motivation, construction, and use of our systems designed for the everyday care of our families. As both makers and users, autobiographical design [47] enables access to interactional nuance, which as highlighted in the proposal of Design Memoirs [19], can foreground complex emotional narratives for shared contemplation. Sharing of autobiographical experiences also raises ethical concerns [16] regarding the potential impacts towards other closely related people. We approach this by omitting names and faces of our family members, receiving consent (from those who can) following a review of this manuscript, and by being transparent regarding our intentions to how designing for the caring of "loved ones" might be approached differently within interaction design as a result of our sharing.

In addition, a first-person critique as reflexively oriented towards ourselves lies in a recognition of our positionalities as dynamic in response to sharing experiences and ongoing interpretations [8, 32]: how we interpret our designs now might differ from our initial intentions. In this respect, our critique aligns with Light's queering as a method [44] in that we are not concerned with "outing" values of the designs then or now; and instead are interested in an ongoing mutability of our designs "that allows new truths, perspectives and engagements to emerge through a refusal to accept definition" [44]. By drawing upon ideas of troubling [15, 28, 61], this tactic explicitly problematizes care as "straight" within our designs to makes space for other values and lifestyles, and can be seen in related HCI research on disrupting toxic status quos [30], promoting inclusion and diversity [55], and questioning gendered stereotypes [56, 58]. Although similar to Søndergaard's [61] articulation of troubling design, we are hesitant to broadly conceptualize this research as "queer" or "queering" as it risks decentering gender and sexuality in favor of a situated perspective of the "normative" [72] that we are challenging within care. As highlighted by Hardy and Lindtner [29], "[q]ueerness and queering means not only reinterpreting the heteronormative for new queer uses, but also reinterpreting the queer for further queer meaning".

We do further play upon the idea of queering as a "space-making exercise" [44] by drawing upon the concept of orientations in queer phenomenology [2] in which Ahmed describes as starting points for apprehending "a shared inhabitance of people, objects, and spaces". Moreover, she explains that "[o]rientations involve directions toward objects that affect what we do, and how we inhabit space"[2]. Through this lens, care can be viewed as bodily and spatial with different meanings being "a matter of different orientations that [are taken] towards the objects that [care] comes into contact with" [2]. Thus, rather than focusing only on "who" is on either end of caregiving and care-receiving, a queer phenomenology of care might 

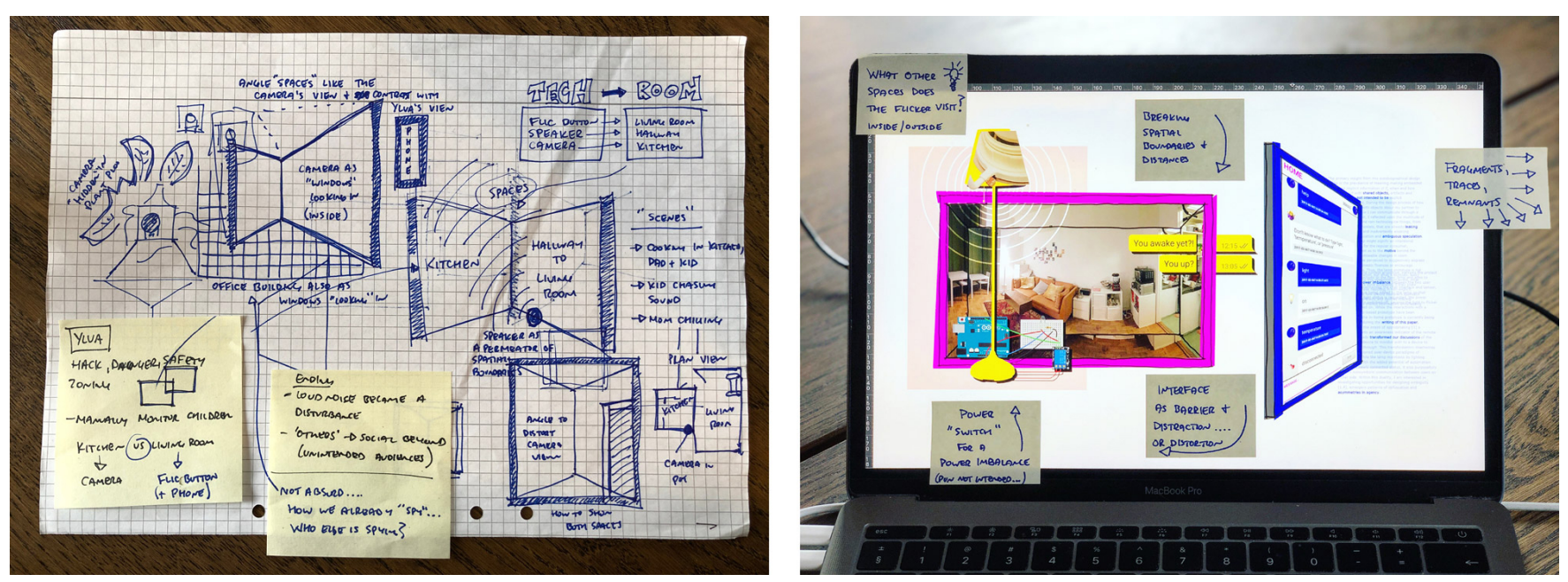

Figure 1: Examples from our process: outlining through sketching physical locations, boundaries, and bodies (left), conceptualizing how care was directed through annotating a collage (right)

orient towards and around other bodily inhabitants and dwellings for new perspectives and alignments that are not "in-line" with normative expectations and directions.

More practically, in approaching our own care practices as spatial, we adopted the following process for our critique. We first wrote autobiographic accounts of the two projects that are later presented in this paper. Following subsequent re-readings of these accounts, in a second step we next outlined physical locations, boundaries, and bodies proximate to our care (see Figure 1, left image). This was accomplished through a revisiting of process documentation, photos, code, disassembled prototypes, and professional depictions of the projects. The latter included an internal publication by Fernaeus, and published papers and a poster presentation by Helms that are either centered around [31] or feature [33, 34] her project, as well as an external publication on tensions in autobiographical design [16] for which she was interviewed about her project relative to earlier publications. From these re-readings and revisitings, we thirdly conceptualized how care was directed across, around, through, or from spaces (see Figure 1, right image). This conceptualization took two forms: a) as collages to help us remember, visualize, and share spatial arrangements; and b) as single word semantic directions, such as detour and shortcut, to help us describe care as spatial and not "in-line" with normative expectations. Each word was then subsequently positioned in relation to care's three dimensions, labor/work, affect/affections, and ethics/politics, from which we reflected upon an uneven distribution and corresponding tension. Our fifth and final step was a grounding of each tension against cultural and gendered expectations of caring for loved ones to position each direction as an orientation. This led us to four troubling orientations of domestic care to guide a critique of the two projects: willful detours, selfish shortcuts, naughty invasions, and unhappy departures.

As previously mentioned, although we draw upon queer theories, we describe the orientations as "troubling" rather than "queer" because not all orientations challenge heteronormative constructs and might instead be interpreted as reinforcing heteronormative roles within their challenging of expectations of domestic care. Next we will present two short narratives describing the projects from our personal viewpoints, directly followed by the critical analysis based on the four troubling orientations. Thereafter follows a short discussion on how these orientations as a conceptual resource helped us in articulating how wickedness may play out in design efforts that address the caring of loved ones.

\section{AUTOBIOGRAPHICAL DESIGN PROJECTS}

In the following we present two autobiographical design projects from the first-person perspective of the designer/author. For each project we describe the project's motivation, design and technical setup, narrative of use, and reasons why it was discontinued. These details should be read as reflective accounts grounded in our memories and process documentation as a way to reassemble and revisit the projects years later.

The two authors are referred to as Wife and Mother throughout the remainder of the text. Wife refers to the first author, and as a label intends to brings attention to her status as a white woman in a legally recognized heteronormative relationship, which often results in an increase of unequal care responsibilities in the home [56]. Wife and her husband are both from North America and currently reside in Northern Europe. Mother refers to the second author, and as a label brings attention to her role as a white woman with three children in a heteronormative relationship. Mother, her partner, and her children are from and reside in Northern Europe. While both labels in their use might perpetuate the stereotypes within the caring for loved ones, we find them important in situating the designs and our positionalities, and in unsettling care through exaggeration.

\subsection{Wife caring for her husband}

This project took place in early 2017 and involved the remote monitoring of sensors at home to speculate about the wellbeing of my partner. In the first iteration of the project, the sensors included a 


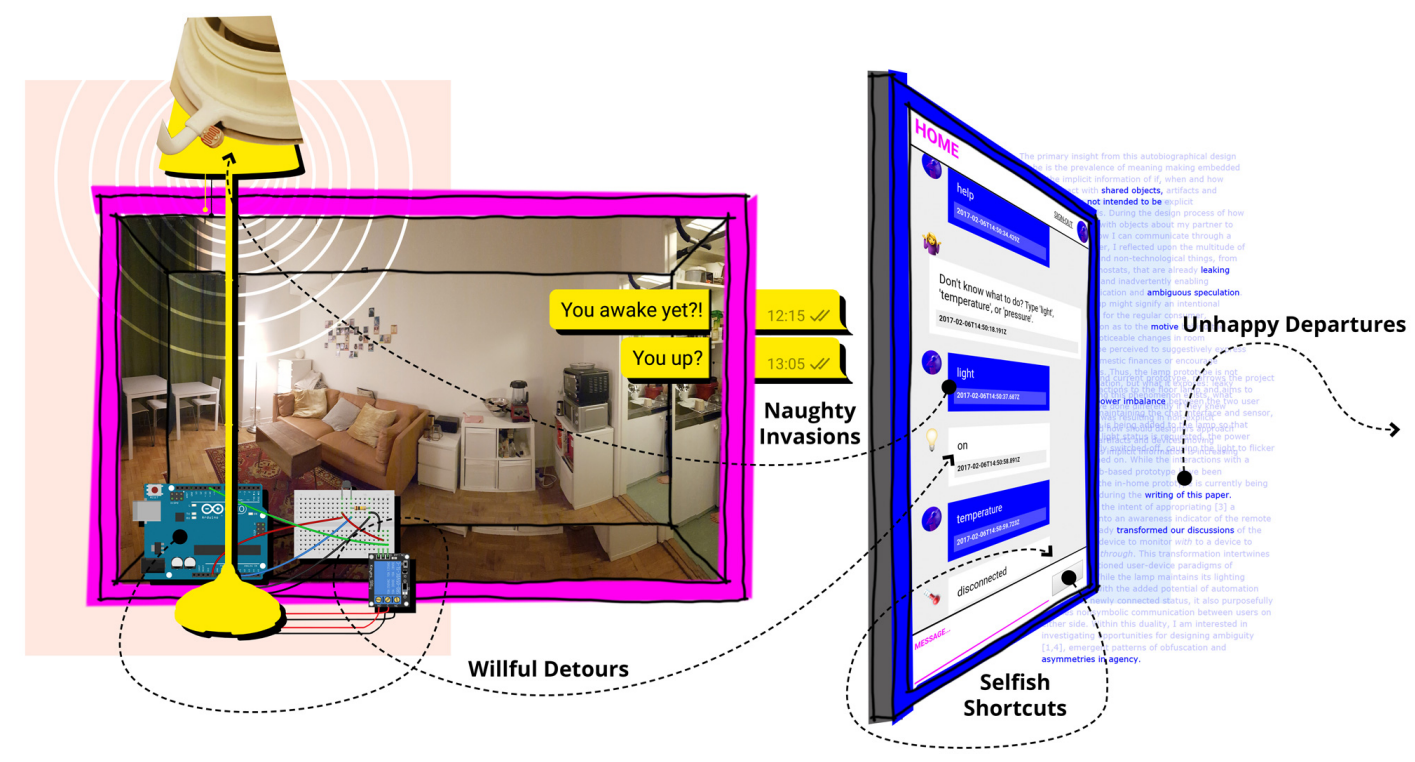

Figure 2: Collage of a Wife caring for her husband superimposed with diagrams of four troubling orientations

temperature sensor above the stove, a pressure sensor underneath a couch cushion, and a photocell light sensor on a floor lamp shade. Upon typing the name of a sensor into a custom web-based chat application, I could access their raw data values or receive a disconnected status if no value could be read or sent. The second iteration of the project included only the photocell attached to the lamp, for which I set approximate data thresholds that corresponded to the light being on or off. I also incorporated a custom power-switch so that whenever the sensor status is requested and the light is already on, the power supply is briefly switched off, which would cause the light to flicker. From conception to deployment, these first and second iterations of the project lasted approximately three months, with a majority of this time frame involving design and implementation.

This project was motivated by concerns for my partner after he and I internationally relocated to Stockholm for my new job. Coinciding with our move, my partner resigned from his employment to take time away from work before exploring new career paths. This resulted in new and often unpredictable daily routines for him, whereby I was curious about the unfolding of each day. From a lack of regular familiarities to inquire into, such as how an important meeting went, I wondered if there were other ways we could communicate about his days during this transition. This was our fourth international relocation together in ten years, and within the previous three, one was jointly for studies and the other two involved us relocating for his job. Thus, my daily curiosities were entangled with concerns for his emotional well-being based on my own experiences of adjusting to a new city and culture while searching for employment. In response, rather than directly probing his routines and well-being through existing communication channels (e.g. a chat application already in use, a phone call, or in-person when I was not at work), I wondered if we could communicate indirectly with each other through the status of shared things. This desire for a new method of communication avoided what I worried would be perceived as nagging: a repetitive inquiry of "are you okay?".

Together we discussed the possibility of indirectly communicating with things about each other, and what information might already exist from our everyday interactions with shared objects in our oneroom studio apartment. This brainstorm led to the first project iteration whereby light from the floor lamp might indicate he is awake and at home, pressure on the couch might mean he is using his computer and online, and heat by the stove might signify current or recent cooking. The indication of these activities did not intend to directly map to an interpretation of his well-being, but rather would allow me to speculate upon their ambiguity guided by my intimate knowledge of him. Three corresponding sensors were rudimentarily taped to the objects and connected to an Arduino Yún that sent the sensor statuses to an online database. I then built a custom web-based (HTML and favaScript) chat interface from which I could query the individual sensor status. The chat interface was minimally styled to easily request information, rather than a continuous broadcasting of sensor activity.

Although consent was given and the status of the sensors could be accessed by either myself or him in a reverse scenario, the power imbalance in favor of myself became embarrassingly obvious. To compensate for this asymmetry of interaction, I kept only the light sensor and appropriated a power switch as a previously mentioned awareness indicator. Narrowing down to a single sensor was thought to create more ambiguity due to less data and thus more privacy for him. The addition of a light flicker as an awareness indicator was thought to lessen my power by exposing my data requests.

In the end, the project only continued for a few weeks after the second iteration. There wasn't a formal decision or joint discussion that marked its ending, but rather I was only using it a few times per week and this use eventually stopped altogether without a direct acknowledgement from either of us as to why. Retrospectively, I now attribute this unremarkable phasing out to his involvement in increasingly 
structured activities and our settling into social routines, both of which reduced space for ambiguity and my genuine need for such a system.

Alongside this diminished use, I began reflecting about this project from an interaction design research lens, which included both writing about and presenting the project in work settings (textual snippets seen in Figure 2). Both during and after the project's use, I often found myself explaining how much "he doesn't care" that I was remotely monitoring him, while often also inserting details that supported the presentation of a stable relationship to further justify the project. But I do think he cared and still does, as he cares about my work and understood this project as related; yet this remains intimately difficult to articulate.

\subsection{Mother caring for her children}

This project took place in late 2018 and involved a small "hack" as an attempt to manage while being home alone with my 18 month old twins, as they were both simultaneously testing out all potential dangers in our home. While our home was already child-proofed to a degree well beyond what we had ever considered with our first child, the twin parenthood still felt like it posed challenges of supervision beyond what I could manage, not least as one of the toddlers typically would move out of sight while I needed to momentarily attend to the other child. As an HCI researcher, and with knowledge and curiosity towards the wide availability of affordable sensors and smart cameras that could be programmed to recognise not only movement and sound but also more specific actions, the development of technology to enhance child safety in home environments became an intriguing domain for me to explore further, on a personal level. The hack was using readily available so called "smart" gadgets and systems: a wifi-enabled motion-sensitive security camera, a bluetooth speaker, a smart physical button (flic), all set up and coordinated wirelessly using software running on my phone.

The basic idea for my intervention was that if a child would move into an unsafe zone or activity, a warning signal would trigger, calling for immediate attention/action, as well as potentially distracting the child away from unsafe activity. In the envisioned design concept, the alarm would trigger automatically, however for the purpose of my first exploration it was set up in a Wizard of $\mathrm{Oz}$ fashion: as a parent I would manually monitor the children, and when observing a child entering the kitchen I'd press the physical flic button to trigger a random sound file to play in the living room. The action also triggered a recording of the video stream from the kitchen view, for documentation purposes. The sounds were a selection of ten short audio clips not commonly played out in the home environment, such as sirens, animal sounds, and other playful noises. Central to the design was a so called "smart" surveillance camera, which was discretely yet clearly visibly placed in one of the flower pots hanging in the kitchen window, so that a live overview feed from the kitchen could be followed on a smartphone from an adjacent room, or elsewhere.

Even if it felt strange to equip our home with a system to help keeping track of our children from another room, there already existed a range of baby monitors with live media feeds, various smart alarm functions, and added features such as both-way communication between child and parent. Moreover, the design concept was motivated by what I had read in advice for parents, that small children do not respond well to negative feedback and are poorly equipped to make sense of complex relations such as cause and effect, and their language and social skills are still underdeveloped. Distraction is therefore one of the recommended strategies to help steer small children away from unwanted behaviour, which has proven more successful than for instance simply trying to tell the child off. Care obviously had to be put into several aspects crucial for this design. Some issues where critical from an ethics or safety point of view, e.g. making sure the system did not counteract its purpose by encouraging rather than preventing unsafe actions. This was addressed primarily by ensuring the design to be "invisible" for the child, both physically and in terms of causal relationship between own action and system response. Secondary design elements included variation of response (i.e. different sounds), and also by the response happening elsewhere (i.e. hearing it play from another room).

Thus, the hack could be motivated as a smart home system to support families with young children to prevent accidents by automatically distracting a child when approaching an unsafe area in the home. Although set up only for this purpose, the surveillance camera almost immediately started to get used for other purposes, as for instance seen in Figure 3, showing a snapshot from checking how far the pancake making was going with my partner and the older child.

On its most basic level, the system worked well; the child running off would typically reorient and run back to check what the noise was all about. However, for many good reasons, this design concept never went beyond the status of the Wizard of $\mathrm{Oz}$ experiment.

First of all, with multiple children in the house, the loud noise became quite a disturbance for us all, especially as it was played even louder in the living room where the rest of the family were typically located. Thus the siblings would get more startled by the sound than the one the sound was intended for. So while focusing perhaps too much on the relationship between parent and child running away, and the potential presentations of media expressed through the system, I hadn't sufficiently acknowledged the existence and perspectives of other family members, or others who may be present in our home.

Secondly, I found it weirder than expected to watch my own children from another room. Although I would constantly keep an eye on them anyway and quite often with camera in hand, the strangeness of being able to overlook an activity from another room felt inherently wrong. In one way this feeling surprised me, as of course a toddler wouldn't care much and this was for their security, and perhaps I could also have got used to it. Having seen the camera view of the kitchen also added a disturbing sense of "what if" other, unseen and unknown, spectators would be able to spy on our family dinners? The camera made us reflect on our kitchen as a private space, which again was surprising, as there were already potential neighbors across the street who already had a good view into our kitchen. My partner also didn't appear entirely on board with the tech-enhanced mode of motherhood that I sneaked into our family home, and to ensure a happy ending of the project I simply took down the security camera and ended the experiment.

\section{FOUR TROUBLING ORIENTATIONS}

We now present critical readings of the two autobiographical projects through four troubling orientations: willful detours, selfish shortcuts, naughty invasions, and unhappy departures. Willful detours 


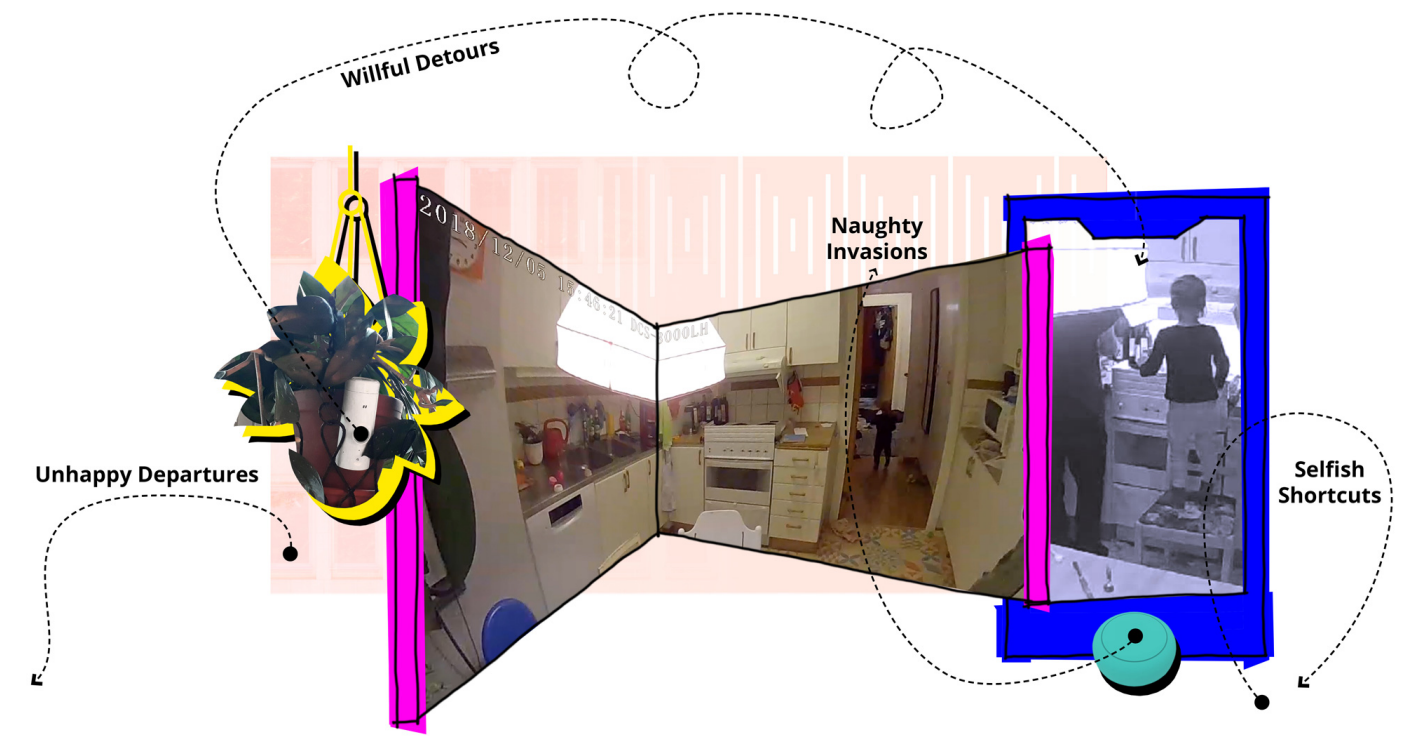

Figure 3: Collage of a Mother caring for her children superimposed with diagrams of four troubling orientations

highlight tensions in affect/affection by violating notions of "as well as possible" through inefficient and unoptimized care. Selfish shortcuts foreground tensions in ethics/politics through a prioritization of one's own "good" life over loved ones. Naughty invasions bring attention to tensions in labor/work through unwelcome exposures of care doings. Unhappy departures emphasize tensions in affect/affection when traces of care diverge in new directions that do not feel good. Within each, we further highlight an uneven distribution of care's three dimensions and the bodily ways in which humans, technologies, and spaces are oriented.

\subsection{Willful Detours}

Willful detours go against feminized expectations of domestic care through inefficient and unoptimized performances of care work. They challenge a politics of care through the actualization of care labor, which results in tensions in the affective "as well as possible" of what might be considered "good" domestic care. We consider these detours because they do not reduce care labor, but create additional roundabout work in caring through designing, making, and monitoring; and we consider them willful [5] because they deliberately deviate from expectations of caretakers.

While both projects can be considered "quick and dirty" hacks relative to low fidelity details and technological appropriations, there was still time dedicated to the design of the systems to enable caring across spatial boundaries. These efforts rejected other readymade solutions that might be considered more in-line with our roles as a Wife and Mother: such as Wife efficiently extending from work to home through a phone call or Mother effectively corralling her twins in a confined space. Furthermore, the projects created even more work from this other work of designing. For Wife, this additional work involved requesting sensor status data about home through the custom chat interface from work; and for
Mother, additional work involved monitoring the camera feed in the kitchen from her smart phone in the living room.

Although the activities require very little physical effort, there is time and attention directed away from what is spatially proximate towards cares in other physical spaces through the availability of sensor statuses. In this regard, the sensors give access to caring detours, by which we both were able to take alternative routes in the caring for our loved ones. These routes are alternative because of the quick glimpses afforded by the photocell and camera as sensors that did not necessitate physically moving our attention and bodily presence to perform care work as might be culturally expected of us. Instead, we were able to transverse spatial boundaries by doing other, additional and indirect work of designing, building, and hacking the systems.

In Western contexts, feminized expectations of domestic work have a cultural history of optimization through the "process of training oneself to identify typical causes for interruptions and [as] a system to take care of such issues without encroaching on a prioritized schedule" [26]. By contrast, our data glimpses deliberately steered away from optimization, and as such might be considered willful in their explicit opposition to efficiency. Furthermore, the furtive nature of the glimpses counter formulaic models of care whereby peeking at just enough information about a remote physical space opened more expansive speculative spaces of interpretation for Wife and forecasting for Mother.

Thus, in both projects the affective "caring about" became the laborious "caring for" in the additional and unbounded work involved in creating the systems and monitoring the sensors. In this way, our designs as deviant and deviating routes violate notions of "good" domestic care as systematic and streamlined. To be clear, it's not that we didn't care, it's that we willfully cared differently in our additional care doings, within which we perhaps could even have been considered to have cared more. 


\subsection{Selfish Shortcuts}

Selfish shortcuts achieve self-care by unintended or appropriated use of systems designed for the care of others. While care work is directed towards someone else, the affective disposition is directed towards oneself through reduced labor. This results in ethical tensions regarding who's "good" life is prioritized as self-care is accelerated through the "piggybacking" on systems built on the premise of centering others. Thus, these systems are selfish in their redirection of attention at the potential detriment of others.

Although the two projects elicited more labor as previously described, they simultaneously "freed" us from other tasks and preoccupations. Through indirect inquiry, Wife avoided being perceived as nagging, and in doing so she could also orient her speculations towards her husband being "okay" rather than potentially facing verifiable evidence or a direct response of him not doing well. As a shortcut, she was able to be "away" [35] from affective responsibilities through redirecting attention towards how she felt and how she wanted him to feel; and as a result, she risked not being aware of her husband not being okay.

Through remote monitoring, Mother was freed from being in the same room as her kids and of potentially navigating them away from unsafe situations. These freedoms reduced physical childcare responsibilities whereby she could engage in other spatially present activities of her choice, such as watching TV. While the multitasking housewife/mother is often considered a trope of women's oppression that technology can intensify by increasing opportunities for "ands" of care-taking [18], such as cooking and cleaning, Mother's multitasking differed in that her "and" was not explicitly directed towards the well-being of her children or the well-being of herself for the wellbeing of her children, but towards her own entertainment. In effect, her shortcutting physical labor through multitasking could have also been a distraction that interfered with child oversight and safety response time.

This redirecting of caring for others to caring about ourselves can be seen as a form of self-care in its most basic aim to "feel good". The selfish nature of our prioritization over others aligns with neoliberal models of self-care as "treat yourself" [36], yet differs in a lack of moralized self-optimization through Mother's unproductive multitasking and Wife's inefficient speculating. Furthermore, the selfish nature of our appropriation of built systems centered around others capitalizes on an invisibility of care labor often contested in feminist self-care movements, which in our an exploitation of technology could be seen as a political strategy for collective survival [36].

This unresolved positioning and the resulting ethical tensions of our shortcuts are indicative of "the symbiotic and at times contradictory relationship between self-care and care for others" [36] Through appropriation, the systems decentered others for our own well-being. Yet despite possible risks, the centering of ourselves did not eliminate affect and labor towards our families, for which we position the shortcuts as selfish.

\subsection{Naughty Invasions}

Naughty invasions make "invisible" care labor overt through affective disobedience. This deliberate exposure of care work results in tensions of how a "good" life is pursued, and in doing so, redirects attention from care-receiving toward care-giving. They are naughty in their playful refusal to not be seen, and invasions in their being seen as the unwelcome capturing of attention or filling of space.

In acknowledgment of a felt power imbalance, Wife integrated a power-switch to expose her remote checking of the light sensor. The resulting flickers invaded the surrounding environment as an unsolicited system feature by her husband that originated in her own ethical concerns. In addition, actuation was dependent on when Wife felt moved to care, rather than when her husband might benefit from receiving care through the revealing of her care-giving. As a flicker only showed if he was there and if the light was on, it could have been obstructed by her husband simply turning off the light altogether. This condition delegates privacy as a user responsibility rather than inherent to design [73] and further shifts, rather than balances, how power is distributed. Thus, despite Wife's well-meaning intentions to communicate a subtle "I'm thinking of you," the flickers were visually "loud" as uninvited and unanticipated spatial transformations.

The audio clips from Mother's system can similarly be seen as invasions. They also originated from her own felt need and design conceptualization rather than a need or solution directly expressed from her children, in addition to their actuation based on Mother's preemptive assessment of a potentially unsafe situation. The audio clips as sounds not commonly associated with a home environment that were grounded in an explicit intent to distract, compounded by their ability to pervade adjacent rooms, furthers them as intrusive from the perspective of the children, and even more so from the perspective of a sibling or the father as potential bystanders. In these regards, while Mother was motivated by a "good" life for her children through a caring for their safety, this aim was accomplished by audio that deliberately interfered with ongoing activities in other spaces.

The naughtiness of both designs can be interpreted in the deliberate play with surveillance technology as culturally taboo and in the corresponding irony of making our surveillance obvious. The former attempts to frame "spying on loved ones" as possibly flirty in the case of Wife or silly in the case of Mother, yet the invasive qualities from displacing care from a wife and mother to technology also position them as potentially creepy or annoying. The latter exposes what wives and mothers are often expected to discreetly do: "watch" over a husband without nagging or "entertain" children through a silly tune.

Although the projects were motivated by ethics of care, the actualization of care as affectively intrusive does not resolve concerns for power and safety. Instead, the potential effects of making care labor unexpectedly and playfully evident through the occupation of remote spaces results in further tensions. Thus, Wife and Mother could be considered naughty in their disobedience of how care is blatantly executed.

\subsection{Unhappy Departures}

Unhappy departures generate ethical concerns from remnants of exposed care labor. They depart from histories of care in new and unexpected directions, resulting in tensions towards the original "as well as possible" design intentions. Departures are inheritances [50] in that they are not left behind or merely stay in the past, but 
are brought forward for continued impressions and expressions of care by givers, receivers, and others. Departures become unhappy when expectations of happiness [3] from care work are obfuscated by different narratives of how a "good" life is pursued.

Wife often found herself explaining how her partner did not mind her monitoring of the sensors and him. She often further justified potential consequences of the project to colleagues, such as a breakup, by voluntarily offering details that exemplified the stability of their relationship. Inheritances of care to depart from included professional traces of use, such as presenting the project as autobiographical research in professional settings; as well as narratives of their relationship history, such as how long they have been together and the previous moving hardships they have overcome. The former often resulted in departures by others, from which she often felt her caring intentions were misunderstood as caring for a loved one seemed to be re-framed as spying on a loved one. The latter can be seen as her attempt to offer traces for other departures in other directions.

By contrast, Mother often found herself departing from original intentions of caring for her children to care for other activities, such as how the pancake making was progressing. Her own departures prompted other uncomfortable departures regarding the ease at which herself, through the hack and neighbors, through the kitchen window, can watch on her loved ones. In response to her partner's hesitations and her own re-framing of what might be considered spying on loved ones, she disassembled the project. Although despite its ending, similar to Wife, there might still be traces of our care work for future departures from colleagues, neighbors, and ourselves.

Also, an aspect not yet known at the time of the experiment concerns how one of the twins was later diagnosed with hearing impairment. The child hears loud noises and therefore responded to the system, but needs a hearing device to pick up all the nuances of everyday speech. As then unknown, the well-intended Mother thus designed a system that in hindsight appears almost brutal in terms of carelessly neglecting the special needs of this particular child. This points to the very concrete reality of caring for small children with potentially hidden disabilities, but also to hidden personal problems of loved ones any age, as when revealed often result in feelings of remorse or unhappiness within those who care for them.

The unhappiness of the designs and their departures lay within our expectations of caring for our loved ones to feel good, yet inevitably not feeling good in response to subsequent impressions by others and ourselves. Happiness [3] can be described as a promise through the proximity to certain objects whereby "if you do this or if you have that, then happiness is what follows." We were happy in proximity to the original intents of the project, and then became unhappy as departures of care created proximity to other possible readings and speculations.

Unhappy departures bring attention to the work in "caring for" becoming the "caring about" something else. Traces of care labor can be starting points for caring departures that might re-frame shared backgrounds and safe spaces as unhappy pursuits of a "good" life. In this way, caring never ends and instead continually transforms through inherited departures that might conflict with promises of happiness.

\section{DISCUSSION}

From a reflexive critique of two autobiographical projects, we have drawn upon queering as a method to trouble caring for loved ones as not "in-line" with normative expectations and as a conceptual "space-making" exercise. From our critique, we have shown four possible "un-straight" orientations that are both a spatial direction and a position that takes into account an unequal distribution of care's three dimensions: willful detours, selfish shortcuts, naughty invasions, and unhappy departures.

As a result, the four orientations surface other values, structures, and lifestyles beyond expectations from which the everyday caring for loved ones is often celebrated and moralized. Our approach draws attention to a revealing of tensions within care's three dimensions of affect/affective, labor/work, and ethics/politics. We next consider contradictory desires for and against such tensions as a "wickedness" that needs caring for within technologicallymediated care more broadly. We then discuss the four orientations as generative paths for interaction designers in troubling care by approaching it as bodily and spatial. Lastly, we offer a broader methodological reflection on what it means to be a careful and/or wicked researcher.

\subsection{Caring for Wickedness in Design}

In exploring tensions as inseparable from an unequal distribution of care's three dimensions, we see them as potentially to be desired. For example, in willful detours, the creation of more inefficient work for ourselves is seen to trouble problematic cultural expectations of care to be optimized. Such expectations can and often result in additional digital labor to managing care-giving (e.g. [1]) that can be counterproductive towards a continuation of unrecognized gendered work in the home [26]. By contrast, our willful detours care more by also implicitly caring for, through a troubling of, a broader politics of how technological solutions can create more invisible labor at the expense of "virtually absent" humans [27]. Similarly, through the appropriation of systems centered on others to care for ourselves, selfish shortcuts highlight access to an affectively "light" care as reassuring amid pressures to care more or about unwanted concerns. Technological systems such as social media platforms can provide meaningful access to the personal sharing or global calling of care needs; while critical for the survival of many, can also be overwhelming. Selfish shortcuts demonstrate caring less at the potential expense of others as a political refusal to care more [4].

Yet of course, inherent to tensions of care are conflicting concerns and power imbalances that might also cause harm in our own or another care context. For example, in naughty invasions, an unwelcome filling of space might feel annoying, creepy, or taunting depending on who is present and how the presence of technology is exposed. The design fiction Uninvited Guests [60] explores how providing care for loved ones at a distance might compromise human agency and autonomy through persistent notifications that interrupt and attempt to control routines. An obfuscation of naughty invasions to avoid unwanted and potentially threatening exposure of care-giving, such as turning off the light in Wife's project, risks the disruption of communication channels that might also be critical for the well-being of isolated care receivers. Through a focus on 
care as transformative, unhappy Departures raise new and possibly unanticipated ethical concerns from remnants of care labor that can reframe original intentions or open uncomfortable narratives. Digital and physical traces of caring can remain long after a project has ended, such as in this paper or related publications [31]; and while a collaborative authorial voice [16] in some circumstances might avoid uncomfortable misunderstandings, it could also mask or conceal conflict. Inheritances of labor or histories of affect can also serve as narrative justifications within real or speculative abusive uses of technology [10].

As previously mentioned, this contradictory appeal for and against tensions highlights a "wickedness" within care that aligns with the notion of "wicked problems" [52]. Similar to Devedorf et al. [18], we hesitate to broadly imply that caring for loved ones requires problems that should "fix" the home or its inhabitants as in need of hegemonic solutions, but do want to stay with a potential violence that is inseparable from engaging with care beyond simplifications of it as positive and fulfilling. In making space for care as transformative and troubling, as not "in-line" with normative expectations and directions, a "wickedness" in design recognizes and seeks to make mischief of its inherent dimensions rather than attempting to resolve tensions at the expense of potential divergent care practices. As highlighted by related work, a careful approach for one situation might be a careless approach for another situation; and as highlighted by our projects, staying with the tensions between careful and careless can open for an attractive naughtiness in a seemingly careless situation and a potential violence in a seemingly careful situation.

\subsection{Designing for a Wickedness in Care}

To explore designing with a wickedness of care as non-linear and non-conforming, we approached care as spatial by drawing upon the concept of orientations in Queer Phenomenology [2]. Orientations are both the directions that care takes towards objects and a style that affects how we inhabit space. As described by Ahmed, "[s]pace then becomes a question of 'turning,' of directions taken, which not only allow things to appear, but also enable us to find our way through the world by situating ourselves in relation to such things" [2]. From this perspective, queering as a method became a literal and metaphorical "space-making exercise" [44] from which tensions of care can be reflected upon or generatively designed with. We see the orientations that we discovered as four possible paths for interaction designers, either as in our case to support self-criticism of autobiographical designs, and also to trouble uses and misuses beyond oneself and beyond one's own design efforts.

In describing the four orientations as not "in-line" with normative expectations and directions, we refer to them as "troubling" rather than "queer" [61] despite drawing upon queer theories and queering as a spatial term. While we position all four orientations as disruptive to status quo, not all challenge heteronormative constructs and might instead even be interpreted as reinforcing them within caring for loved ones. For example, selfish shortcuts unsettles contradictory expectations between caring for oneself and caring for others, and yet in doing so also remains aligned with Western notions of individualism and heteronormative partnerships. Thus what each orientation troubles is situated within constructs of what might be considered "normative" care at home.

In returning to wickedness as an attractive naughtiness, this framing may help in diversifying the notions and understandings of what technology-mediated care is and what it could be. "Care" might also be conceptually understood as implicit in settings in which it may not be explicitly stated or considered. This further implies being aware of the tensions and power relations, which includes the potential playful clowning that might make it a bit naughty, and also the potential violence that can occur, whether directly or as a departure. The four troubling orientations could thus be read as unstraightening devices [2] that help designers conceptually connect back to care as non-linear, refusing to be "'straight' as an effect of constant repetition and reproduction of these expectations and alignments" [2]. Thus, what it means to approach domestic care as bodily and spatial is about not separating relations of care from our bodily ways of inhabiting the world. Approaching care in this way can open up a design space whereby tensions could be resources for considering values and lifestyles that might differ from situated, yet thick and often contradictory, stereotypical expectations of designing with care.

\subsection{Careful Design Research}

Here we offer a methodological reflection regarding doing autobiographical work with our families and a critique of this work that challenges dominant ways of belonging as designers and researchers. In a sense, we can easily imagine how our interventions might be considered insignificant in light of world-wide challenges of meeting global care needs. We ourselves have at times felt tempted to dispel them as mere "wicked solutions to personal problems", with personal problems as pointing to something of non-interest by anyone outside of our own homes, and which we attempted, but failed to address. Needless to say, our privileged positions as academics, along with our statuses as white, Western, cis women cannot be neglected here. Within both of the projects presented, we experienced a sense of "naughtiness" as both autobiographical researchers and participants, and also as partners and a mother within the quirky interactions designed for our families. This brings to our mind similar concerns as those brought up by Brown et al.'s [13] study on the interpersonal complexities of conducting field trials in the wild, and for instance how users implicitly or explicitly may attempt to be a "good participant", which naturally comes with its own bias. As autobiographical design researchers, we similarly find ourselves reflecting on what it means to be "good participants" here, in our dual relationships of designing for ourselves and our loved ones, but simultaneously also for a research community within which we want to belong.

This calls for new conceptual tools for the design community to better support analysis and criticism of projects immersed in intimate settings, to unpack the implicit, sometimes unwanted, nonstereotypical, or wicked qualities of care as expressed in real life and in the works of design. We believe the four conceptual directions that we explore may work as one such resource, and which may also be useful for other researchers as a framework to guide or start new and other explorations. In particular, we found the approach of articulating and describing potentially "un-straight" directions of 
care, inspired by space making as described by feminist and queer theory, helpful in conceptual mapping of a complex design space.

We also would like to highlight the values that we experience in the revisiting of design work over time (short-term and longterm) in relation to changes in positionality, as also previously experienced by Helms [32] through the shifting roles and contexts of ourselves and others. For example, in considering "unhappy departures", life situations are as such ephemeral and looking back at them adds new layers that bring something inherently different than as was once there. In particular, our experiences from looking back now from the outside to craft the reflections presented, helped us in articulating how designing for loved ones need to be locally and temporally caught, yet with space that allows them to float away and themselves to turn into objects of storytelling. In that sense, they become personal histories, but also help reflecting on the complexities of autobiographical research practices.

\section{CONCLUSION}

Caring for loved ones is an increasingly relevant issue for interaction design, not least in the light of the ongoing pandemic, as families worldwide have shared new demands of practices and routines related to home-office and home-schooling, caring for vulnerable family members at a distance, quarantine regulations resulting in physical separations between partners, and simply staying connected with friends. A central part in these practices is appropriation of new and technologically mediated ways of caring. Through critiquing two autobiographical design projects designed for informal, everyday care of our families, we argue that careful design cannot be disconnected from particular interpersonal contexts of use, and how tensions in care can be desired and generative, but also loading design efforts with alternative meanings. Through our analysis we discovered four troubling orientations for articulating how designing for the care of loved ones could be "un-straight", or wicked: willful detours, selfish shortcuts, naughty invasions, and unhappy departures. We concluded by discussing a "wickedness" in caring for loved ones that complicates in-home technologies as attractively naughty and potentially violent, and the four orientations as resources for interaction designers to navigate within the wicked design space of care.

\section{ACKNOWLEDGMENTS}

Our families. This work was supported by the Swedish Foundation for Strategic Research project RIT15-0046.

\section{REFERENCES}

[1] [n.d.]. HomeRoutines App. http://www.homeroutines.com/

[2] Sara Ahmed. 2006. Queer Phenomenology: Orientations, Objects, Others. Duke University Press. https://doi.org/10.1215/9780822388074

[3] Sara Ahmed. 2010. The Promise of Happiness. Duke University Press. GoogleBooks-ID: uOAPdbhSpksC.

[4] Sara Ahmed. 2014. Selfcare as Warfare. https://feministkilljoys.com/2014/08/25/ selfcare-as-warfare/

[5] Sara Ahmed. 2014. Willful Subjects. Duke University Press. Google-Books-ID hx3IBAAAQBAJ.

[6] Madeline Balaam, Rob Comber, Rachel E. Clarke, Charles Windlin, Anna Ståhl, Kristina Höök, and Geraldine Fitzpatrick. 2019. Emotion Work in ExperienceCentered Design. In Proceedings of the 2019 CHI Conference on Human Factors in Computing Systems (CHI '19). Association for Computing Machinery, Glasgow, Scotland Uk, 1-12. https://doi.org/10.1145/3290605.3300832
[7] Jeffrey Bardzell. 2011. Interaction criticism: An introduction to the practice. Interacting with Computers 23, 6 (Nov. 2011), 604-621. https://doi.org/10.1016/j. intcom.2011.07.001

[8] Jeffrey Bardzell, Shaowen Bardzell, and Lone Koefoed Hansen. 2015. Immodest Proposals: Research Through Design and Knowledge. In Proceedings of the 33rd Annual ACM Conference on Human Factors in Computing Systems - CHI '15. ACM Press, Seoul, Republic of Korea, 2093-2102. https://doi.org/10.1145/2702123. 2702400

[9] Genevieve Bell and Paul Dourish. 2007. Yesterday's tomorrows: notes on ubiquitous computing's dominant vision. Personal and Ubiquitous Computing 11, 2 (Feb. 2007), 133-143. https://doi.org/10.1007/s00779-006-0071-x

[10] Rosanna Bellini, Emily Tseng, Nora McDonald, Rachel Greenstadt, Damon McCoy, Thomas Ristenpart, and Nicola Dell. 2020. "So-called privacy breeds evil": Narrative Justifications for Intimate Partner Surveillance in Online Forums. Proceedings of the ACM on Human-Computer Interaction 4, CSCW3 (2020), 210:1-210:27. https://doi.org/10.1145/3432909

[11] Cynthia L. Bennett, Daniela K. Rosner, and Alex S. Taylor. 2020. The Care Work of Access. In Proceedings of the 2020 CHI Conference on Human Factors in Computing Systems (CHI '20). Association for Computing Machinery, Honolulu, HI, USA, 1-15. https://doi.org/10.1145/3313831.3376568

[12] Shruti Bhandari and Shaowen Bardzell. 2008. Bridging gaps: affective communication in long distance relationships. In CHI '08 Extended Abstracts on Human Factors in Computing Systems (CHIEA '08). Association for Computing Machinery, New York, NY, USA, 2763-2768. https://doi.org/10.1145/1358628.1358758

[13] Barry Brown, Stuart Reeves, and Scott Sherwood. 2011. Into the wild: challenges and opportunities for field trial methods. In Proceedings of the SIGCHI Conference on Human Factors in Computing Systems (CHI '11). Association for Computing Machinery, New York, NY, USA, 1657-1666. https://doi.org/10.1145/1978942. 1979185

[14] Barry Brown, Alex S. Taylor, Shahram Izadi, Abigail Sellen, Joseph Jofish' Kaye, and Rachel Eardley. 2007. Locating Family Values: A Field Trial of the Whereabouts Clock. In UbiComp 2007: Ubiquitous Computing (Lecture Notes in Computer Science), John Krumm, Gregory D. Abowd, Aruna Seneviratne, and Thomas Strang (Eds.). Springer, Berlin, Heidelberg, 354-371. https://doi.org/10.1007/9783-540-74853-3_21

[15] Judith Butler. 2006. Gender Trouble: Feminism and the Subversion of Identity. Routledge.

[16] Audrey Desjardins and Aubree Ball. 2018. Revealing Tensions in Autobiographical Design in HCI. In Proceedings of the 2018 Designing Interactive Systems Conference (DIS '18). ACM, New York, NY, USA, 753-764. https://doi.org/10.1145/3196709. 3196781

[17] Audrey Desjardins, Jeremy E. Viny, Cayla Key, and Nouela Johnston. 2019. Alternative Avenues for IoT: Designing with Non-Stereotypical Homes. In Proceedings of the 2019 CHI Conference on Human Factors in Computing Systems (CHI '19). Association for Computing Machinery, New York, NY, USA, 1-13. https://doi.org/10.1145/3290605.3300581

[18] Laura Devendorf, Kristina Andersen, and Aisling Kelliher. 2020. The Fundamental Uncertainties of Mothering: Finding Ways to Honor Endurance, Struggle, and Contradiction. ACM Transactions on Computer-Human Interaction 27, 4 (Sept. 2020), 26:1-26:24. https://doi.org/10.1145/3397177

[19] Laura Devendorf, Kristina Andersen, and Aisling Kelliher. 2020. Making Design Memoirs: Understanding and Honoring Difficult Experiences. In Proceedings of the 2020 CHI Conference on Human Factors in Computing Systems (CHI '20). Association for Computing Machinery, Honolulu, HI, USA, 1-12. https://doi. org/10.1145/3313831.3376345

[20] Patty Douglas, Carla Rice, and Christine Kelly. 2017. Cripping Care: Care Pedagogies and Practices. Review of Disability Studies: An International fournal 13, 4 (Dec. 2017). https://www.rdsjournal.org/index.php/journal/article/view/779 Number: 4.

[21] Megan L. Evans, Margo Lindauer, and Maureen E. Farrell. 2020. A Pandemic within a Pandemic - Intimate Partner Violence during Covid-19. New England fournal of Medicine 383, 24 (Dec. 2020), 2302-2304. https://doi.org/ 10.1056/NEJMp2024046 Publisher: Massachusetts Medical Society _eprint: https://doi.org/10.1056/NEJMp2024046.

[22] Ylva Fernaeus, Maria Håkansson, Mattias Jacobsson, and Sara Ljungblad. 2010. How do you play with a robotic toy animal? a long-term study of Pleo. In Proceedings of the 9th International Conference on Interaction Design and Children (IDC '10). Association for Computing Machinery, New York, NY, USA, 39-48. https://doi.org/10.1145/1810543.1810549

[23] Sarah Fox. 2018. Design, Maintenance, and the Menstruating Body. In Proceedings of the 2018 ACM Conference Companion Publication on Designing Interactive Systems (DIS '18 Companion). ACM, New York, NY, USA, 375-378. https://doi. org $/ 10.1145 / 3197391.3205386$

[24] Beurer GmbH. [n.d.]. Baby monitors | beurer. https://www.beurer.com/web/gb/ products/babycare/babyphone/

[25] Google. [n.d.]. Nest Cam Indoor. https://store.google.com/product/nest_cam

[26] Melissa Gregg. 2018. Counterproductive: Time Management in the Knowledge Economy. Duke University Press. Google-Books-ID: dQ5zDwAAQBAJ. 
[27] Melissa Gregg and Rutvica Andrijasevic. 2019. Virtually Absent: The Gendered Histories and Economies of Digital Labour. Feminist Review 123, 1 (Nov. 2019), 1-7. https://doi.org/10.1177/0141778919878929 Publisher: SAGE Publications.

[28] Donna J. Haraway. 2016. Staying with the Trouble: Making Kin in the Chthulucene Duke University Press. Google-Books-ID: ZvDgDAAAQBAJ.

[29] Jean Hardy and Silvia Lindtner. 2017. Constructing a Desiring User: Discourse, Rurality, and Design in Location-Based Social Networks. In Proceedings of the 2017 ACM Conference on Computer Supported Cooperative Work and Social Computing (CSCW'17). Association for Computing Machinery, New York, NY, USA, 13-25. https://doi.org/10.1145/2998181.2998347

[30] Ellie Harmon, Matthias Korn, Ann Light, and Amy Voida. 2016. Designing Against the Status Quo. In Proceedings of the 2016 ACM Conference Companion Publication on Designing Interactive Systems (DIS '16 Companion). Association for Computing Machinery, New York, NY, USA, 65-68. https://doi.org/10.1145/2908805.2913020

[31] Karey Helms. 2017. Leaky Objects: Implicit Information, Unintentional Communication. In Proceedings of the 2017 ACM Conference Companion Publication on Designing Interactive Systems (DIS '17 Companion). Association for Computing Machinery, Edinburgh, United Kingdom, 182-186. https://doi.org/10.1145/ 3064857.3079142

[32] Karey Helms. 2019. Do You Have to Pee? A Design Space for Intimate and Somatic Data. In Proceedings of the 2019 on Designing Interactive Systems Conference (DIS '19). Association for Computing Machinery, San Diego, CA, USA, 1209-1222. https://doi.org/10.1145/3322276.3322290

[33] Karey Helms. 2020. Careful Design: Implicit Interactions with Care, Taboo, and Humor. In Companion Publication of the 2020 ACM Designing Interactive Systems Conference (DIS' 20 Companion). Association for Computing Machinery, New York, NY, USA, 515-519. https://doi.org/10.1145/3393914.3395827

[34] Karey Helms, Barry Brown, Magnus Sahlgren, and Airi Lampinen. 2018. Design Methods to Investigate User Experiences of Artificial Intelligence. In 2018 AAAI Spring Symposium Series. https:/www.aaai.org/ocs/index.php/SSS/SSS18/paper/ view/17527

[35] Karey Helms, Pedro Ferreira, Barry Brown, and Airi Lampinen. 2019. Away and (Dis)connection: Reconsidering the Use of Digital Technologies in Light of Long-term Outdoor Activities. Proceedings of the ACM on Human-Computer Interaction 3, GROUP (Dec. 2019), 230:1-230:20. https://doi.org/10.1145/3361111

[36] Hi 'ilei Julia Kawehipuaakahaopulani Hobart and Tamara Kneese. 2020. Radica Care: Survival Strategies for Uncertain Times. Social Text 38, 1 (142) (March 2020), 1-16. https://doi.org/10.1215/01642472-7971067 Publisher: Duke University Press.

[37] Dorothy Howard and Lilly Irani. 2019. Ways of Knowing When Research Subjects Care. In Proceedings of the 2019 CHI Conference on Human Factors in Computing Systems (CHI '19). Association for Computing Machinery, Glasgow, Scotland Uk, 1-16. https://doi.org/10.1145/3290605.3300327

[38] Kristina Höök, Baptiste Caramiaux, Cumhur Erkut, Jodi Forlizzi, Nassrin Hajinejad, Michael Haller, Caroline C M Hummels, Katherine Isbister, Martin Jonsson, George Khut, Lian Loke, Danielle Lottridge, Patrizia Marti, Edward Melcer, Florian Floyd Müller, Marianne Graves Petersen, Thecla Schiphorst, Elena Márquez Segura, Anna Ståhl, Dag Svanaes, Jakob Tholander, and Helena Tobiasson. 2018. Embracing First-Person Perspectives in Soma-Based Design. Informatics 5, 1 (Feb. 2018). https://doi.org/10.3390/informatics5010008

[39] Tom Jenkins, Anna Vallgårda, Laurens Boer, Sarah Homewood, and Teresa Almeida. 2019. Careful Devices. In Proceedings of the Halfway to the Future Symposium 2019 (HTTF 2019). Association for Computing Machinery, New York, NY, USA, 1-5. https://doi.org/10.1145/3363384.3363474

[40] Joseph 'Jofish' Kaye and Liz Goulding. 2004. Intimate objects. In Proceedings of the 5th conference on Designing interactive systems: processes, practices, methods, and techniques (DIS '04). Association for Computing Machinery, Cambridge, MA USA, 341-344. https://doi.org/10.1145/1013115.1013175

[41] Joseph 'Jofish' Kaye, Mariah K. Levitt, Jeffrey Nevins, Jessica Golden, and Vanessa Schmidt. 2005. Communicating intimacy one bit at a time. In CHI'05 Extended Abstracts on Human Factors in Computing Systems (CHI EA '05). Association for Computing Machinery, New York, NY, USA, 1529-1532. https://doi.org/10.1145/ 1056808.1056958

[42] Masako Kitazaki, Iohanna Nicenboim, and Elisa Giaccardi. 2019. Connected Resources - Empowering Older People to Age Resourcefully. In Extended Abstracts of the 2019 CHI Conference on Human Factors in Computing Systems (CHI EA '19). Association for Computing Machinery, New York, NY, USA, 1. https://doi.org/ $10.1145 / 3290607.3311774$

[43] Tama Leaver. 2017. Intimate Surveillance: Normalizing Parental Monitoring and Mediation of Infants Online. Social Media + Society 3, 2 (April 2017), 2056305117707192. https://doi.org/10.1177/2056305117707192 Publisher: SAGE Publications Ltd.

[44] Ann Light. 2011. HCI as heterodoxy: Technologies of identity and the queering of interaction with computers. Interacting with Computers 23, 5 (Sept. 2011), 430-438. https://doi.org/10.1016/j.intcom.2011.02.002

[45] Michelle Murphy. 2015. Unsettling care: Troubling transnational itineraries of care in feminist health practices. Social Studies of Science 45, 5 (Oct. 2015), 717-737. https://doi.org/10.1177/0306312715589136
[46] Michelle Murphy. 2017. The Economization of Life. Duke University Press.

[47] Carman Neustaedter and Phoebe Sengers. 2012. Autobiographical Design in HCI Research: Designing and Learning Through Use-it-yourself. In Proceedings of the Designing Interactive Systems Conference (DIS '12). ACM, New York, NY, USA, 514-523. https://doi.org/10.1145/2317956.2318034

[48] Doenja Oogjes, William Odom, and Pete Fung. 2018. Designing for an other Home: Expanding and Speculating on Different Forms of Domestic Life. In Proceedings of the 2018 Designing Interactive Systems Conference (DIS '18). Association for Computing Machinery, New York, NY, USA, 313-326. https://doi.org/10.1145/ 3196709.3196810

[49] Leah Lakshmi Piepzna-Samarasinha. 2018. Care Work: Dreaming Disability fustice. Arsenal Pulp Press. Google-Books-ID: QDFbDwAAQBAJ.

[50] María Puig de la Bellacasa. 2017. Matters of Care: Speculative Ethics in More Than Human Worlds. University of Minnesota Press, Minneapolis.

[51] Anuradha Reddy. 2020. Researching IoT through Design : An Inquiry into BeingAt-Home. Ph.D. Dissertation. http://urn.kb.se/resolve?urn=urn:nbn:se:mau:diva17852 Publisher: Malmö universitet.

[52] Horst Rittel. 1984. Second-Generation Design Methods. Developments in Design Methodology (1984), 317-327. https://ci.nii.ac.jp/naid/10000152286/ Publisher: John Wiley \& Sons, New York.

[53] UN Secretary-General. 2020. Policy Brief: The impact of COVID-19 on women. Technical Report. https://www.unwomen.org/en/digital-library/publications/ 2020/04/policy-brief-the-impact-of-covid-19-on-women

[54] William Seymour, Reuben Binns, Petr Slovak, Max Van Kleek, and Nigel Shadbolt. 2020. Strangers in the Room: Unpacking Perceptions of 'Smartness' and Related Ethical Concerns in the Home. In Proceedings of the 2020 ACM Designing Interactive Systems Conference (DIS '20). Association for Computing Machinery, Eindhoven, Netherlands, 841-854. https://doi.org/10.1145/3357236.3395501

[55] Katta Spiel, Os Keyes, Ashley Marie Walker, Michael A. DeVito, Jeremy Birnholtz, Emeline Brulé, Ann Light, Pınar Barlas, Jean Hardy, Alex Ahmed, Jennifer A. Rode, Jed R. Brubaker, and Gopinaath Kannabiran. 2019. Queer(ing) HCI: Moving Forward in Theory and Practice. In Extended Abstracts of the 2019 CHI Conference on Human Factors in Computing Systems (CHI EA '19). Association for Computing Machinery, New York, NY, USA, 1-4. https://doi.org/10.1145/3290607.3311750

[56] Yolande Strengers and Jenny Kennedy. 2020. The Smart Wife: Why Siri, Alexa, and Other Smart Home Devices Need a Feminist Reboot. MIT Press. Google-Books-ID: TL34DwAAQBAJ.

[57] Yolande Strengers, Jenny Kennedy, Paula Arcari, Larissa Nicholls, and Melissa Gregg. 2019. Protection, Productivity and Pleasure in the Smart Home: Emerging Expectations and Gendered Insights from Australian Early Adopters. In Proceedings of the 2019 CHI Conference on Human Factors in Computing Systems (CHI '19). Association for Computing Machinery, New York, NY, USA, 1-13. https://doi.org/10.1145/3290605.3300875

[58] Yolande Strengers, Lizhen Qu, Qiongkai Xu, and Jarrod Knibbe. 2020. Adhering, Steering, and Queering: Treatment of Gender in Natural Language Generation. In Proceedings of the 2020 CHI Conference on Human Factors in Computing Systems (CHI '20). Association for Computing Machinery, New York, NY, USA, 1-14. https://doi.org/10.1145/3313831.3376315

[59] Interaction Research Studio. [n.d.]. Yo-Yo Machines. https://www.yoyomachines. io

[60] Superflux. [n.d.]. Uninvited Guests. https://superflux.in/index.php/work/ uninvited-guests/

[61] Marie Louise Juul Søndergaard. 2020. Troubling Design: A Design Program for Designing with Women's Health. ACM Transactions on Computer-Human Interaction 27, 4 (Aug. 2020), 24:1-24:36. https://doi.org/10.1145/3397199

[62] Marie Louise Juul Søndergaard and Lone Koefoed Hansen. 2018. Intimate Futures: Staying with the Trouble of Digital Personal Assistants through Design Fiction. In Proceedings of the 2018 on Designing Interactive Systems Conference 2018 - DIS '18. ACM Press, Hong Kong, China, 869-880. https://doi.org/10.1145/3196709. 3196766

[63] Alex S. Taylor and Laurel Swan. 2005. Artful systems in the home. In Proceedings of the SIGCHI Conference on Human Factors in Computing Systems (CHI '05). Association for Computing Machinery, New York, NY, USA, 641-650. https: //doi.org/10.1145/1054972.1055060

[64] Javier Tibau, Michael Stewart, Steve Harrison, and Deborah Tatar. 2019. FamilySong: Designing to Enable Music for Connection and Culture in Internationally Distributed Families. In Proceedings of the 2019 on Designing Interactive Systems Conference (DIS '19). Association for Computing Machinery, New York, NY, USA, 785-798. https://doi.org/10.1145/3322276.3322279

[65] Austin Toombs, Laura Devendorf, Patrick Shih, Elizabeth Kaziunas, David Nemer, Helena Mentis, and Laura Forlano. 2018. Sociotechnical Systems of Care. In Companion of the 2018 ACM Conference on Computer Supported Cooperative Work and Social Computing (CSCW'18). Association for Computing Machinery, Jersey City, NJ, USA, 479-485. https://doi.org/10.1145/3272973.3273010

[66] Austin Toombs, Shad Gross, Shaowen Bardzell, and Jeffrey Bardzell. 2017. From Empathy to Care: A Feminist Care Ethics Perspective on Long-Term Researcher-Participant Relations. Interacting with Computers 29, 1 (Jan. 2017), 45-57. https://doi.org/10.1093/iwc/iww010 Conference Name: Interacting with 
Computers.

[67] Austin L. Toombs, Andy Dow, John Vines, Colin M. Gray, Barbara Dennis, Rachel Clarke, and Ann Light. 2018. Designing for Everyday Care in Communities. In Proceedings of the 2018 ACM Conference Companion Publication on Designing Interactive Systems (DIS '18 Companion). Association for Computing Machinery, Hong Kong, China, 391-394. https://doi.org/10.1145/3197391.3197394

[68] Joan C. Tronto. 1993. Moral Boundaries: A Political Argument for an Ethic of Care. Psychology Press.

[69] Joan C. Tronto. 2015. Who Cares?: How to Reshape a Democratic Politics (1 ed.). Cornell University Press. https://www.jstor.org/stable/10.7591/j.ctt18kr598

[70] Frank Vetere, Martin R. Gibbs, Jesper Kjeldskov, Steve Howard, Florian 'Floyd' Mueller, Sonja Pedell, Karen Mecoles, and Marcus Bunyan. 2005. Mediating intimacy: designing technologies to support strong-tie relationships. In Proceedings of the SIGCHI Conference on Human Factors in Computing Systems (CHI '05). Association for Computing Machinery, New York, NY, USA, 471-480. https://doi.org/10.1145/1054972.1055038

[71] Mark Weiser. 1999. The Computer for the 21st Century. SIGMOBILE Mob. Comput. Commun. Rev. 3, 3 (July 1999), 3-11. https://doi.org/10.1145/329124.329126

[72] Robyn Wiegman and Elizabeth A. Wilson. 2015. Introduction: Antinormativity's Queer Conventions. differences 26, 1 (May 2015), 1-25. https://doi.org/10.1215/ 10407391-2880582

[73] D. E. Wittkower. 2020. Privacy as Care: An Interpersonal Model of Privacy Exemplified by Five Cases in the Internet of Things. In Relating to Things: Design, Technology and the Artificial. Bloomsbury Academic. 